\title{
O PENSAMENTO PÓS-MODERNO SOBRE A CULTURA DO ESPÍRITO TOLERANTE: O SOLAPAR DO IRRACIONALISMO NA MODERNIDADE PELA PERSPECTIVA ANTI-HISTÓRICA
}

\author{
Silvia Rosa Silva Zanolla*
}

\section{RESUMO}

O intuito deste artigo é fixar algumas reflexões acerca do denominado pensamento pós-moderno de Jean F. Lyotard. Suas implicações, no âmbito cultural, atingem, entre outros, conceitos como história, filosofia, razão, utopia, tecnociência e subjetividade. Para tanto, buscou-se na teoria crítica de Herbert Marcuse parâmetros de análise.

Palavras-chave: pós-modernidade e teoria crítica, irracionalismo, crise da razão, crise da modernidade, crise da utopia, crise do iluminismo.

\section{O SUJEITO PERMISSIVO OCULTO PELA SUBJETIVIDADE DO TOTALITARISMO: A DESLEGITIMAÇÃO DA CONTRA- DIÇÃO ILUMINISTA}

Não é, portanto, de admirar que, nos setores mais desenvolvidos dessa civilização, os controles sociais tenham sido introjetados a ponto de até o protesto individual ser afetado em suas raízes. A negativa intelectual e emocional de "prosseguir" parece neumática e impotente. Esse é o aspecto sócio-psicológico do acontecimento

\footnotetext{
"Professora da Faculdade de Educação da Universidade Federal de Goiás. [e-mail: silviarosasilva@bol.com.br]
} 
político que marca o período contemporâneo: o desaparecimento das forças históricas que, na fase anterior da sociedade industrial, pareceu representarem a possibilidade de novas formas de existência. (MARCUSE, 1967)

A necessidade de pensar a cultura atual na relação com o universo material, suas determinações e perspectivas rumo à possibilidade de uma razão crítica, leva a refletir os mecanismos adotados pela sociedade moderna nas defesas do controle e do investimento da consciência manipulada, de um sujeito ignorante de si mesmo. Esse tipo de irracionalidade é traduzida por um pensamento anti-histórico cultural, oculto por uma espécie de racionalidade totalitária; a reposição da repressão e da dominação através do controle que impede a tensão entre os acontecimentos históricos e as afirmações do presente, relativizando as possibilidades de transformações sociais futuras. A pós-modernidade representa bem essa racionalidade anti-histórica. Suas idéias referentes à crise da razão, crise da modernidade e crise do iluminismo refletem o postulado da cultura irracional contemporânea. Diante dessa irracionalidade, interessa menos defender aspectos históricos do ideário iluminista ou moderno e mais defender as suas contradições culturais e sociais justificadas, segundo o liberalismo, pelos anseios de liberdade, o que, ignorado pelos pós-modernos, impede o ideal utópico da transformação social. Para tal tarefa, é necessário entender o significado histórico da modernidade e do ideário liberal.

Embora no século XVIII as idéias de liberdade se vinculassem ao projeto liberal, essa realidade era buscada na forma de uma razão utópica que encontrava motivos na própria razão de constituição: $a$ liberdade era uma meta, mesmo que ideológica. Estavam dadas as contradições daquela modernidade que, por um lado, anunciava um sujeito livre, e, por outro, incentivava o capitalismo na exploração em todos os sentidos, humana e material. ${ }^{1}$ As suas contradições podiam esclarecer as mudanças básicas de estruturas que deram forma ao mundo moderno e estão no reconhecimento de seu continuísmo histórico. Por outro lado, sabemos que existem rupturas necessárias às transformações que engendram a ação política dos indivíduos e 
que poderiam ser apontadas como descontinuístas, tais como o início e o fim de períodos considerados como marcos históricos para as mudanças sociais. Mas isso não significa uma ruptura radical com o passado.

Segundo Barrocloug (1964, p. 37), “Todos os rótulos que colocamos em determinado período são ex-post-facto (olhando-paratrás)". Dentro da nossa perspectiva, essa afirmação pode ser complementada por Harvey, ainda podemos sentir o período moderno, pois seu vir-a-ser é uma aspiração histórica. Para esse autor, na essência, na pós-modernidade, o que está em jogo é menos a questão histórica e mais a perda de princípios humanos de justiça, o que impede transformações futuras:

Na consciência o presente só é válido em virtude das potencialidades do futuro, como a matriz do futuro, na medida em que ele é a força da história em contínua metamorfose, vista como uma revolução espiritual permanente. (HARVEY, 1973, p. 326)

A pós-modernidade não é uma questão de simples negação da modernidade e da história, mas a tentativa de impor uma cisão entre uma e outra. Para entender isso não se pode ignorar o ideário iluminista que, apesar de contraditório, representa as aspirações humanas da modernidade e sua relação com a noção histórica de sujeito verdadeiramente livre.

Como se percebe, a negação do ideário iluminista pelo movimento pós-moderno possui na própria razão de ser a impossibilidade de existência crítica, justificada pela crítica, ou melhor, pela falsa crítica. Essa inversão atinge várias áreas do conhecimento como arte, literatura, filosofia, sociologia e arquitetura; porém, a discussão estética e literária é objeto para outra discussão. Aqui o que interessa, além de discutir os argumentos de combate à modernidade, é a crítica à perspectiva de totalidade e universalidade das teorias sociais pelos pós-modernos, acarretando a defesa da subjetividade no sentido puramente ontológico. Uma subjetividade individualista que, segundo o pós-moderno Lyotard (1990), encontra-se na modernidade subjugada pelos valores universais iluministas. Assim, para continuar a discussão, 
não parece oportuno apresentar as razões culturais do movimento pós-moderno sem submetê-lo a um pequeno mapeamento.

A escola francesa, desde a década de 1950, com suas idéias de decadência e crise da razão, traz uma versão derrotista e niilista da modernidade representada pelo pensamento pós-moderno de Lyotard. ${ }^{2}$ Esse niilismo vulgar se torna mais aparente conforme avança influenciando a cultura política e acadêmica, implicando em decadência da reflexão sobre os fatores históricos de dominação implícitos na cultura. Abrem-se assim as portas para a ignorância, o desconhecimento e a inépcia teórico-política.

No âmbito acadêmico, as análises pós-modernas recaem em interpretações deslocadas de seu verdadeiro sentido, a sua essência ideológica. Isso pode ser percebido quando Lyotard (1990) refere-se aos conflitos dos fenômenos modernos, como advindos da chamada crise da razão, os quais, na perspectiva de outros teóricos, como Adorno e Horkheimer (1985) e Marcuse (1967), são explicados como contradições da razão, ou seja, uma espécie de irracionalismo técnico em meio à razão lógico-formal, perspectiva que, de maneira alguma, abre mão da importância histórica. A idéia de crise da razão reflete em âmbito particular a concepção de subjetividade pósmoderna. Em Lyotard (1990), essa concepção faz com que a discussão acerca da perspectiva de consciência - esta conquistada ou não pelo indivíduo - torne-se puramente defesa de autoconstituição individualizada, independente de sua consciência de sujeito social. A noção de ser indivíduo é inviabilizada por ela mesma, justificada pela negação do sujeito pelo que se pretende ser sujeito. Essa idéia vai ao encontro da definição de pseudo-individuação, trabalhada por Adorno (1984, p. 115)

A relativização da subjetividade em Lyotard é acompanhada pelo caráter permissivo da pós-modernidade, ${ }^{3}$ permitindo em âmbito geral e acadêmico a vulgarização tanto da ciência quanto da filosofia.

Confesso-te que educar me parecem nem mais nem menos actos filosóficos do que uma pessoa banquetear-se ou equipar um navio. (LyOTARD, 1993, p. 119) 
Para Lyotard (1990, p. 100), contrapondo-se à visão universal do conhecimento, é preciso "pesquisar e inventar o contra-exemplo, isto é, o ininteligível: trabalhar na argumentação é pesquisar o paradoxo". Essa argumentação é justificada pela aceitação de um pluralismo que vai além do ecletismo, não apresenta qualquer rigor ou critério de racionalidade. Trata-se do investimento em um indivíduo no sentido específico, não social. Inexiste na cultura pós-moderna a pretensão à seriedade filosófica ou teórica, a definição de parâmetros de análise. Coelho Neto (1995, p. 2) situa bem isso:

Não havia flechas para o arco. Mas não tem importância porque tampouco havia alvo no qual atirar, moderno e pós-moderno constituem, por enquanto, um vazio em relação ao qual a pósmodernidade é uma flecha ausente.

Essa exacerbação do relativismo pós-moderno vai ao encontro da inversão da crítica, faz com que as contradições históricas da modernidade se nivelem às suas conquistas e ocultem os méritos destas últimas. A crítica à modernidade, à crise, constitui fatalismo racional. Mas, se a pós-modernidade advoga pelo relativismo, qual é o seu verdadeiro sentido?

Segundo Lyotard (1990), a pós-modernidade na década de 1950 configura a transição da modernidade para uma sociedade mais avançada e crítica ao desenvolvimento industrial após a Segunda Guerra Mundial. Novos valores aparecem, e o ideário moderno é questionado. A transição é acompanhada de um crescente desenvolvimento da indústria tecnológica e do redimensionamento cultural de um novo indivíduo, fruto de uma nova liberdade admitindo várias realidades individuais, contrastando com a definição de realidade histórica, sentimento utópico e transformação social. Esse argumento parte teoricamente da crítica aos valores universais das narrativas sociológicas, históricas e filosóficas, valores meramente burgueses. De acordo com Lyotard (1990), as narrativas universais realizam-se em nome da humanidade para defender projetos totalitários e ao mesmo tempo individuais. Essa perspectiva, de outro lado, inverte o sentido da totalidade ao totalitarismo, condensa um quadro de perspectivas efêmeras e caóticas de uma 
história fragmentária, descontinuísta e desprovida de utopia sociohistórica. O sentido universal - contraditório, diga-se de passagem - é apresentado como autoritário: "O nós em nome do eu" (LyotaRd, 1990).

Para defender a busca do indivíduo diante das grandes narrativas teóricas, Lyotard (1990) ${ }^{3}$ apresenta o potencial da linguagem humana dentro de um esquema heterogêneo de formas e narrativas pessoais. Essa idéia reflete o combate a autores como Marx e Freud, os quais, segundo o autor, apresentam teorias ultrapassadas e totalitárias, possuindo elaborações teóricas fixas e estáveis, ao mesmo tempo pessoalizadas.

Ao ignorar essas contribuições, Lyotard (1990) ignora também sua importância para o processo de compreensão do sentido da dialética, conceito, aliás, questionado por ele - sua relação com a perspectiva de totalidade em face do que é particular e converte negação em afirmação, pois subverte a universalidade à particularidade. A perspectiva crítica de Lyotard, ao contrário de possibilitar a análise considerando as diferenças entre os aspectos universal e particular, é trabalhada como mediação e unificação de ambos, da mesma maneira que a noção de sociedade livre incorpora-se à visão de um indivíduo já emancipado, que dá conta da realidade social, sem necessariamente transformá-la universalmente.

A nova subjetividade do novo indivíduo, perdido na totalidade do iluminismo burguês, é tarefa pós-moderna. Para Lyotard, a noção de sujeito e subjetividade na realidade confunde-se com aspirações individualistas, relatos e experiências pessoais. Lyotard (1990), ao analisar superficialmente o conceito de subjetividade, anula a perspectiva histórica do sujeito e não vê a impossibilidade de existência de uma realidade transformadora, quando oculta a verdadeira condição de alienação social.

Os argumentos da teoria pós-moderna e a pretensão de inaugurar um novo indivíduo postulam a relativização da perspectiva de consciência política, vulgariza não somente a idéia de razão, como também banaliza e deprecia o que de conflitante existe na história da humanidade, a estrutura de dominação existente. $\mathrm{O}$ anti-historicismo fortalece um individualismo renovado resultante do que existe de mais 
conservador na defesa dos interesses privados. Sennet (1993, p. 18) descreve essa situação no âmbito da intimidade:

As sociedades ocidentais estão mudando a partir de algo semelhante a um estado voltado para o outro, para um tipo voltado para a interioridade - com ressalva de que, em meio à preocupação consigo mesmo, ninguém pode dizer o que há dentro. Como resultado, originou-se uma confusão entre vida pública e vida íntima: as pessoas tratam em termos de sentimentos pessoais os assuntos públicos, que somente poderiam ser adequadamente tratados por meio de códigos de significação pessoal.

A conversão da totalidade em totalitarismo transforma a possibilidade de liberdade em opressão, quando esta é associada à emancipação. Ao inverter esses sentidos não se distingue situações divergentes, o conformismo se assenta na irracionalidade aliado ao anti-historicismo que desmemoria o indivíduo, facilitando a ilusão de liberdade e irracionalidade, dificultando a crítica verdadeira. Esse tipo de inversão é percebido por Marcuse ao analisar a sociedade moderna após a Segunda Guerra:

Se a racionalidade que progride na sociedade industrial desenvolvida tende a liquidar, como uma pausa irracional, os elementos perturbadores do tempo e da memória, tende também a liquidar a racionalidae perturbadora contida nessa pausa irracional. O reconhecimento e a relação com o passado como sendo presente age contra a funcionalização do pensamento pela realidade estabelecida nela. A mediação do passado com o presente descobre os fatores que fizeram os fatos, que determinaram o estilo de vida, que estabeleceram os senhores e servos; projeta os limites e alternativas. Quando essa consciência crítica fala, ela fala le langage de la connaissance (Roland Bathers). (MARCUSE, 1967, p. 105; grifos do autor)

Na contramão, o anti-historicismo de Lyotard busca uma permissividade ${ }^{4}$ teórica que tolera várias realidades, e não um contexto de realidade. Torna-se inconcebível pensar uma razão histórica, mas, sim, um momento de fusão do presente, passado e 
futuro. Como diria Marcuse (1967), “o que é, jamais poderá sê-lo verdadeiramente, porque jamais o foi", ou seja, a sociedade transformada. Ocorre a inversão do sentido da dialética, do singular e do universal. A subjetividade (singular) é sinônimo de individualidade. Daí a defesa de Lyotard (1993, p. 39) do que denomina pequenas narrativas:

Não haverá nada além de vós e eu. O lugar da pessoa está na palavra política, o trabalhador, a palavra social, o pobre, a palavra econômica, que o singular se apodere do universal e que o último se torne também o primeiro. Estou a simplificar, espero ser desculpado.

Longe de desculpar ou culpar o autor, o problema não é tão simples quanto aparenta. As graves implicações teóricas parecem não chegar a Lyotard. Ao não conceber um contexto real, sua essência e suas possibilidades de alienação perdem-se. Isso facilita uma espécie de conformismo estrutural, tolerado no tempo presente, é a relativização da luta política: "Finalmente é necessário que se torne claro que não nos compete fornecer realidade, mas inventar alusões ao concebível que não pode ser presentificado" (Lyotard, 1993, p. 27).

A abstenção da história consagra a perseguição da modernidade como se fosse uma crítica, resultando na perda do significado das lutas sociais e na tentativa de conter contradições impostas pelo sistema capitalista. A verdadeira crítica à modernidade é anulada à medida que, sem história, não há possibilidade de questionamento do status quo. Assim, o anti-historicismo da pós-modernidade convive harmonicamente com a permissividade e o pluralismo disfarçados de ecletismo.

Segundo os próprios pós-modernos o que justifica sua permissividade é a democracia de idéias. Conforme Marcuse, ao analisar os rumos da sociedade capitalista,

no domínio da cultura, o novo totalitarismo se manifesta precisamente num pluralismo harmonizador, no qual as obras e as verdades mais contraditórias coexistem pacificamente com indiferenças. (MARCUSE, 1967, p. 73) 
Lyotard (1990) admite a permissividade ao mesmo tempo em que deturpa a filosofia como teoria que possibilita conhecimento amplo do indivíduo. Assim, desenvolve a sua fragmentação: "Esta situação indica o que está em jogo no pensamento filosófico hoje. De momento, a defesa das razões opera através de micrologias" (LyOtARD, 1993, p. 79).

Dessa forma, o conhecimento aparece como se fosse um tratado sobre corpos microscópicos, positiviza o sentido antinômico da subjetividade, faz com que esta perca o princípio da autonomia humana mediada pelo social, como amplia Marcuse, ao postular a importância da perspectiva de totalidade. Para ele, a análise deve considerar

o fator externo e o interno visando à percepção da totalidade não no sentido fixo ou permanente, mas que se transcende na tentativa de perceber suas próprias limitações e contradições. (MARCuSE, 1967, p. 20)

Nesse caso, a história é fator condicionante para o reconhecimento das contradições.

A conversão da totalidade em totalitarismo apresenta-se no resgate da subjetividade como um estilo de vida próprio do sujeito cidadão, consciente de seus direitos, porém absorto dos valores utópicos universais, considerados, nesse contexto, obsoletismos da modernidade.

\section{O FIM DA UTOPIA E A CRISE DA RAZÃO: O INDIVÍDUO PAGA O PREÇO DO PROGRESSO}

Considerando que os fenômenos históricos e as aspirações ao ideal de consciência não são o objetivo da racionalidade atual, o novo discurso da pós-modernidade ganha notoriedade de elaboração teórica. A exacerbação do irracionalismo na modernidade supõe fator de presentificação. $\mathrm{O}$ conceito de sujeito, desprovido do passado (história), julga-se isento de avaliações e reflexões rigorosas. Encarar os fenômenos sociais dessa maneira está ligado ao imediatismo no 
pensamento e ao agir irrefletido, obtendo resultados que reproduzem comportamentos mecânicos e acríticos no cotidiano, fortalecendo a primazia da prática ou esta apenas como técnica.

Lyotard julga-se crítico dos efeitos trazidos pela tecnologia moderna, mas confunde história, tecnociência e modernidade, indiscriminadamente. À medida que simplifica e relativiza a análise, limita-a: "A tecnociência realiza o projeto moderno; o homem tornase senhor e dono da natureza" (LYOTARD, 1993, p. 34). A modernidade torna-se sinônimo de tecnologia. Desse modo, confirma uma realidade, mas também não apresenta as contradições da tecnologia e da modernidade, perde a dimensão entre necessidade da razão técnica, limites de sua implantação e possibilidade ou não de reversão.

$\mathrm{O}$ avanço tecnológico é um paradoxo para a humanidade. É preciso dizer que as necessidades humanas se vinculam objetivamente ao meio social, ao mesmo tempo em que se concretizam por meio da dominação da natureza, de acordo com projetos racionais. Essa constatação só poderá se dar com base no reconhecimento da história como fator determinante e na capacidade essencial do homem de superar seu estado natural, buscar a sua essência:

[...] para Marx, exatamente a essência e a facticidade, a situação da história da essência, a situação da história factual não mais são regiões ou níveis separados independentes um do outro: a historicidade do homem está apreendida em sua determinação essencial. (MARCuSE, 1981, p. 35)

Para Marcuse (1967), a essência humana está em que a razão técnica contém a contradição da dominação e do progresso, assim, é irracional como objeto da ciência. Se desprovido, objeto da ciência, de seu reconhecimento como fonte de poder, ainda mais. Esse reconhecimento pode permitir a consciência para a libertação, assegurando que historicamente exista uma tensão entre o que é e o que pode vir-a-ser. Exemplo disso são os benefícios da ciência e, em contraposição, seus malefícios pela forma como é utilizada.

A técnica, assim como o trabalho, não é isenta de responsabilidade na manipulação dos aparelhos de dominação. Afirmar que a dominação técnica é apenas responsabilidade de quem a utiliza seria 
aliviar os seus efeitos contraditórios. O progresso trazido pela técnica não alivia os desafios sociais como a miséria, a violência e a crueldade, "indícios de sofrimento, escassez e carência" (MARcuse, 1981). Desse modo, a contradição do progresso técnico deve ser avaliada sob a perspectiva crítica e histórica proposta por Marcuse (1967), quando denuncia o irracionalismo técnico pela operacionalização do trabalho e da arte. Contextualizando os mecanismos culturais de dominação, será possível a perspectiva do vir-a-ser, a utopia, impossibilitada no imediatismo da visão pós-moderna.

Na pós-modernidade, a utopia do vir-a-ser não encontra lugar. A liberdade ilusória do indivíduo está na tolerância repressiva, que oculta os mecanismos culturais de dominação. A permissividade, como se viu, sustenta a ideologia justificada pela pluralidade. A contradição dessa permissividade irracionalista está em que se perde essência da realidade em meio a um vasto universo de possibilidades, que não permite a constituição de nenhuma. Por falta de parâmetros, torna-se quase impossível questionar na atualidade o significado da liberdade. Segundo Marcuse (1969, p. 14), ao ser desprovida da análise crítica e histórica, a sociedade é entendida como livre por definição; "o movimento histórico vira pré-história da humanidade".

Ao serem inviabilizadas as possibilidades utópicas, a sociedade preserva e reforça os mecanismos de dominação, estimulando o sistema repressor que dá continuidade às necessidades que, por sua vez, são também repressivas. A necessidade utópica de liberdade se relativiza, é ridicularizada pela ilusão de aparente conquista. $\mathrm{O}$ antihistoricismo faz com que a adequação às condições da falsa liberdade impeça necessidades vitais de conquista. Para romper com essa realidade seria necessário não abrir mão da utopia e negar o que está estabelecido. Este seria um movimento no sentido crítico e político, para tentar compreender o quanto a razão historicamente possibilita também a irrazão, o que difere do pensamento pós-moderno, que postula a crise da razão. As razões do controle social possuem determinações objetivas que passam pelo universo subjetivo, ou seja, aspectos universais e específicos, culturais e políticos. Os aspectos culturais de dominação são permeados por necessidades ilusórias e reais de liberdade. 
HERBERT MARCUSE E A BUSCA DO REINO DA LIBERDADE ALÉM DO REINO DA NECESSIDADE - O APRISIONAMENTO DA RAZÃO CRÍTICA PELA CONDIÇÃO DE ADEQUAÇÃO ÀS CONDIÇÕES DA FALSA LIBERDADE ESTABELECIDA

Os efeitos do irracionalismo moderno na sociedade se sedimentam no aspecto material da realidade, mas são fruto de definições produzidas no universo cultural. Desse modo, ao analisar o pensamento pós-moderno, seus princípios - ou a falta destes - e justificativas, é possível perceber que, embora o seu discurso seja o inverso, mantém o que mais critica: o condicionamento e a adequação do indivíduo ao sistema social. Embora não tenha o pensamento pósmoderno sido objeto de Marcuse, este, com base em seus estudos sobre a liberdade repressiva, denominou de reposição da dominação e organização lógica afirmativa do indivíduo ${ }^{5}$ o novo contexto que defende a crise da utopia.

Se a liberdade hoje se dissocia do ideário moderno, isso significa uma utopia ultrapassada. Não possui dentro da teoria pós-moderna o caráter transformador de outrora. A liberdade virou um clichê, pois existem liberdades. As necessidades humanas por liberdade são transferidas para outros patamares de liberdades que, por sua vez, são associadas a outros valores como, por exemplo, o poder de consumo.

Por outro lado, se as forças materiais necessárias para a liberdade já existem em algum lugar como se acredita, qual é o motivo de sua não-concretude? Em Marcuse (1969), essa é uma utopia de uma nova sociedade, onde se deve criar perspectivas como tarefa situada no âmbito do indivíduo na relação com o social.

Para Marcuse, ao contrário de Lyotard (1990), o que impede a transformação da sociedade é a repressão solapada e o imediatamente existente, ou seja, o presente solidificado pela não perspectiva histórica do futuro qualitativo,

Se Marx viu no proletariado a classe revolucionária, isto ocorreu ainda e talvez principalmente porque o proletariado estava liberto 
das necessidades repressivas da sociedade capitalista. Porque nele podiam se desenvolver as novas necessidades de liberdade, que não podiam ser sufocadas por aquelas velhas dominantes. Hoje, na maior parte dos países capitalistas altamente desenvolvidos, essa autonomia não é mais possível. Os trabalhadores não mais representam a classe que leva em si a negação das necessidades existentes. Aliás, esse é um dos mais graves problemas que devemos enfrentar. (MARCuse, 1969, p. 25)

A nova ordem social, segundo Marcuse (1967), encontra-se agora em face da necessidade de enfrentar um ataque global de forças repressivas que se organizam no sentido de resolver os seus problemas de acumulação. Se essa afirmação não fizesse parte de um irracionalismo dominante, não haveria o quadro de exclusão social e, ao mesmo tempo, a apatia em torno dessa realidade. Essa discussão é histórica.

Isso traz um problema para o estudo da subjetividade por meio da análise da cultura. O reino da liberdade só poderá ser construído sobre o reino da necessidade, ou seja, a sociedade livre de hoje encontra em si o inimigo; só poderá ser edificada se for trabalhada num processo contrário a ela, isto é, a liberdade, falsa e contraditória, portanto, carente de desmistificação. Essa desmistificação deverá dar-se não no sentido de simplesmente tentar reverter o quadro natural da história (esse retorno é impossível); assim, deverá acontecer a partir das condições existentes, isto é, da negação da realidade no sentido dialético. Nesse aspecto, a razão deverá estar associada à incapacidade de liberdade da consciência ou ao seu irracionalismo; a dominação encontra-se na falsa idéia de ser racional. Essa contradição demonstra a incompatibilidade entre a harmonia do que é e a tensão do que pode vir-a-ser.

Ao contrário de Marcuse, para Lyotard a crise da razão resolve os problemas da modernidade de maneira simplista. "O termo razão é muito vasto. Aqueles que invocam a razão mantêm a confusão" (LyotARD, 1993, p. 78). Mais uma vez, o raciocínio imediatista e vulgar perde a dimensão da tensão entre razão e irracionalismo. Deixar de questionar a condição histórica de subalternidade do homem é persistir na irrazão, fadá-la à ignorância e à sujeição. Nesse aspecto, não ignorar a cultura pós-moderna constitui uma luta 
contra a perspectiva de razão. O sentido de ruptura entre períodos históricos é acrítico e pressupõe ser uma tendência de dominação que precede a própria modernidade, a tentativa de retardar a consciência de si do sujeito, como forma de manutenção do controle social por meio da cultura.

Por outro lado, é preciso considerar que, embora a cultura atual da modernidade seja encarada pelos pós-modernos como uma tradição a ultrapassar - e por alguns bons intelectuais críticos como uma reação conservadora -, tradição e modernidade não são conceitos estanques, fragmentados. A pós-modernidade não é uma reação conservadora ou nova, é uma idéia falsa de reação. Há nesses conceitos a idéia de um processo descontínuo e ao mesmo tempo contínuo, histórico, que não pode ser encarado simplesmente como uma reação cultural. Afirmar que a pós-modernidade é uma reação fundamenta ainda mais a pretensão de seus defensores de anunciar o novo. A modernidade não é uma bandeira a ser conquistada, nem tampouco a ser combatida, faz-se presente em um contexto que não define os êxitos que alcançou na atualidade. Daí a importância da manutenção da utopia como instrumento de luta social.

E, precisamente porque as chamadas possibilidades utópicas não são absolutamente utópicas, mas antes representam uma determinada negação histórico-social do existente, a tomada de consciência delas - bem como a determinação consciente das forças que impedem a sua realização e que as negam - exigem de nossa parte uma oposição muito realista e muito pragmática, uma oposição livre de todas as ilusões, mas também de qualquer derrotismo, uma oposição que, graças a sua simples existência, saiba evidenciar as possibilidades da liberdade no próprio âmbito da sociedade existente. (MARCUSE, 1969, p. 22)

$\mathrm{O}$ anseio de liberdade da modernidade se faz presente mesmo encoberto pela liberdade repressiva. Sua possibilidade é a própria denúncia contra a razão antimodernista. Por causa disso, o movimento pós-moderno não deve ser negligenciado, sua lógica é muito mais racionalista do que se supõe, cabe, mais do que negá-lo, fazer com 
que suas bases mais alienantes e dominadoras sejam expostas, por mais ocultas que possam parecer.

\section{ABSTRACT}

The aim of this work is to drop some reflections about the named postmodern thought of Jean F. Lyotard. His implications at the cultural extent reach, among others, the concepts as history, filosofy, reason, imagination, technoscience and subjectivity. Then, parameters of analysis was looked for by the critical theory of Herbert Marcuse.

Keywords: post-modern and critical theory, irrationalism, reason crisis, modernity crisis, iluminism imagination crisis.

\section{NOTAS}

1. Adorno e Horkheimer apontam para a contradição do ideário liberal no âmbito cultural e material em Dialética do esclarecimento (1985, p. 81112).

2. Ruy Fausto (1985).

3. Em 1993, Lyotard reforça essas idéias em sua obra $O$ pós-moderrno explicado às crianças (1993, p. 70-77), na qual, de maneira pejorativa, responde às críticas feitas a ele desde a publicação de $A$ condição pósmoderna (1990). O autor critica o que chama de grandes metas narrativas históricas como sendo autoritárias por utilizar o nós em seu discurso. Isso se refere à apropriação dos grandes teóricos que marcaram os séculos XVIII e XIX. O sentido dado a essas teorias por Lyotard considera que o conceito de totalidade é autoritário na perspectiva totalitária.

4. O conceito de permissividade é adotado pelo próprio Lyotard (1993) ao defender a democratização e popularização das idéias. O caráter permissivo da pós-modernidade, traduzida pela escola francesa, segundo Ruy Fausto (1985), impõe em si um desafio na tarefa de situá-la. Isso implica não haver critério suficientemente viável para tal tarefa que não incorra e parâmetro relativizado pelo próprio movimento pós-moderno.

5. Em julho de 1967, Marcuse fazia na Universidade de Berlim Ocidental uma conferência acerca da polêmica sobre o que os intelectuais definiam 
como o fim da utopia: "Este fim da utopia, ou seja, a recusa das idéias e das teorias que ainda servem de utopias para indicar determinadas possibilidades histórico-sociais, podemos hoje concebê-los em termos bastante precisos, também como o que denominam o fim da história" (Marcuse, 1969, p. 13).

\section{REFERÊNCIAS}

BARROCLOUG, F. História e ciência da modernidade. São Paulo: Herder, 1964.

COELHO NETO. A pós-modernidade e o clube de Marx. Rio de Janeiro: Boletim da UFRJ, p. 2, ano III, 1995.

. Moderno pós-moderno. São Paulo: Iluminuras, 1995.

O ESTADO DE S. PAULO. Ruy Fausto manifesta o seu pensar inatural. São Paulo, 18 mar. 1985, p. 15. (Caderno de Cultura).

HARVEY, D. Condição pós-moderna. São Paulo: Loyola, 1993.

ADORNO, T. W.; HORKHEIMER, M. Dialética do esclarecimento: fragmentos filosóficos. Rio de Janeiro: Zahar, 1985.

LYOTARD, J. A condição pós-moderna. Rio de Janeiro: José Olympio, 1990. O pós-moderno explicado às crianças. Lisboa: Publicações D. Quixote, 1993.

MARCUSE, H. A ideologia da sociedade industrial. Rio de Janeiro: Zahar, 1967.

. O fim da utopia. Rio de Janeiro: Paz e Terra, 1969.

1981.

. Idéias sobre uma teoria crítica da sociedade. Rio de Janeiro: Zahar,

SENNET, R. O declínio do homem público - as tiranias da intimidade. São Paulo: Companhia das Letras, 1993. 